\title{
Editorial
}

\section{Costs, revenue, service attributes and competition in shipping}

\author{
Maritime Economics \& Logistics (2012) 14, 265-273. doi:10.1057/mel.2012.7
}

The 2011 Annual Conference of the International Association of Maritime Economists (IAME) was jointly organized by the Transport Research Institute of Edinburgh Napier University and ITMMA of the University of Antwerp and was hosted by the United Nations Economic Commission for Latin America and the Caribbean at their premises in Santiago, Chile. The conference was attended by over 170 delegates from 38 countries and produced numerous papers of high quality. The selection contained within this Special Issue of Maritime Economics and Logistics (MEL) provides merely a representative sample of the best of those papers. The general theme of the IAME 2011 conference was 'Shipping markets, port devolution and a changing geography of world maritime transport'. The editorial team for this special issue has grouped the selected papers under the heading 'Costs, revenue, service attributes and competition in shipping'.

The MEL Prize for Best Paper at the conference was awarded to the first paper selected for inclusion within this Special Issue by Mary Brooks, Sean Puckett, David Hensher and Adrian Sammons. On the back of work undertaken by Brooks and Trifts (2008) within the North American context and the finding of Puckett et al (2011) that shippers will pay for frequency of service, the authors question the widely held assumption or belief that short sea shipping is only competitive with the road mode in freight corridors of a certain minimum distance. Motivated by a desire to inform sound regulatory choices, as well as transport and environmental policy and investment decisions, the authors contend that an in-depth understanding of mode choice decisions needs to be gained through an examination of the trade-offs between price, transit time, frequency and reliability over different corridor distances and modal options.

The paper reports the results from a stated choice experiment, which was conducted with managers responsible for shipping goods between Australian cities in three corridors where competition between modes does, or could, exist. The experiment is designed to elicit respondents' preferred allocations of cargo across the modal alternatives of road, rail and short sea shipping (both domestic and foreign carrier). In doing so, the study identifies and quantifies freight shipper preferences for components of the services offered by alternative modal providers, with each exhibiting distinct attribute values in terms of transit time,

(C) 2012 Macmillan Publishers Ltd. 1479-2931 Maritime Economics \& Logistics Vol. 14, 3, 265-273 www.palgrave-journals.com/mel/ 
frequency, reliability and cost. The specific methodology underpinning the stated choice experiment is innovative in that it not only offers an appealing representation of reliability that facilitates the identification of unique preferences and 'willingness to pay' measures, but also employs proportionate allocation as the basis for exploring modal trade-offs. As freight mode choice decisions are rarely taken on an all-or-nothing basis, the latter involves the specification of a non-binary choice variable that better represents the risk mitigation decisions on route and mode allocation that are taken in practice. Not only does this imply that more behaviourally meaningful choices are presented to respondents within the study, but also that the resulting choice models are better able to capture latent relative preferences for modal alternatives.

The paper concludes that shippers do face meaningful trade-offs between modal attributes, particularly with respect to transit time, on-time arrival reliability and the risk of arrival delays. Short sea shipping is found to attract modal switches from road and rail in the presence of greater reliability and, more specifically, the greater reliability that comes from the integration of short sea shipping services with land-based modes. No 'willingness to pay' was found for national flag services but, as the authors suggest, the value of a national flag fleet may be bound to its ability to deliver on service integration. The paper also concludes that the use of 'willingness to pay' models provides a highly viable and valuable approach to evaluating modal switching under alternative policy options. Most poignantly, however, by applying such a model under diverse scenarios of service mix, transport corridor and cost structure, the cross-price elasticity of demand in the presence of carbon pricing is found to be negligible for modal switching from truck to either rail or sea. Obviously, this has important implications for any prospective regulatory policy, which aims to secure environmental benefits by influencing modal switching.

While service attributes such as transit times, reliability and frequency clearly influence the behaviour of economic actors, it is also clear that the price of shipping has an important part to play in influencing the modal or carrier choice of decision makers. Accurate knowledge of shipping prices, particularly into the future, is fundamental to this and many other strategic decisions. Together with a desire to mitigate the risk associated with freight rate variability, it is this which has motivated numerous studies aimed at forecasting freight rates, particularly in the bulk shipping sector. As efforts continue to improve both the causal modelling of economic time series and the accuracy of forecasting derived therefrom, the development and application of multivariate fuzzy time series forecasting methods (Zadeh, 1965) has emerged as a verdant field of research. Fuzzy time series analysis is basically a method by which forecasts are developed systematically by using fuzzy intervals, which correspond to time series clusters (Song and Chissom, 1993, 1994). It has certain 
advantages over conventional classical time series analysis in that it is useful for both data noise reduction and rule-based forecasting. The paper by Emrah Bulut, Okan Duru and Shigeru Yoshida attempts to improve upon conventional fuzzy time series models by developing a vector autoregressive design for fuzzy extended time series analysis. They illustrate and validate their model by applying it to the forecasting of time charter rates for Panamax and Handymax bulk carriers. In so doing, they lay claim to a particular contribution to the literature in utilizing the $\mathrm{C}$-means clustering method to derive the length of intervals that determine the fuzzy clusters.

The authors compare the accuracy of the forecast results they find from applying their model against those obtained from applying mainstream time series analysis techniques, as well as the classical VAR model and the classical fuzzy time series model (Chen, 1996). Their model is found to outperform all the other benchmark techniques for both in-sample and out-of-sample forecasts, hence validating the causality framework embedded within it. In addition, the classical VAR model is found to be relatively better than other benchmark methods for in-sample accuracy. The authors also find that when applied to the specific time charter rate data set, the classical fuzzy time series model performs even less well than mainstream methods of time series analysis (ARIMA models). The latter finding is particularly interesting in that it implies that the outputs from classical fuzzy time series models should be checked against those derived from applying classical time series approaches, as there may actually be no benefit from deploying the former. Another important finding is that the length of interval chosen for the analysis is found to critically affect the forecasts derived and the subsequent measured accuracy of those forecasts. In this respect, the results obtained support the authors' proposal of the $\mathrm{C}$-means clustering method as the basis for the structuring of the fuzzy length of intervals within the forecasting process and, therefore, for optimizing the distribution of the cluster sets.

In planning how to allocate their available capital at any given point in time, shipping decision makers, but especially shipowners, are constantly faced with selecting between investment alternatives that exhibit very diverse risk/ return ratios. These decisions are complicated by both the magnitude of investments that are required in shipping and by shipping market dynamics that, particularly in the bulk sector, are typically characterized by extreme volatility. Each decision taken represents the application of the decision maker's risk attitude to the risk/return profile of the available alternative investments and reveals the decision maker's propensity to accept risk. At the extreme, such decisions may relate to whether to even have a presence in the shipping market at all; a null investment or even a disinvestment is always an available investment option. More mundanely, however, these asset and contract

\footnotetext{
(C) 2012 Macmillan Publishers Ltd. 1479-2931 Maritime Economics \& Logistics Vol. 14, 3, 265-273 267
} 
management decisions concern the selection of a mix of vessel charter employment so that risk is managed by appropriately combining short-term and long-term contracts in order to reduce exposure to market highs and lows. An alternative conceptualization is provided by Cullinane (1995) who suggests that this amounts to the identification and construction of the optimal portfolio (Markowitz, 1952) of contractual arrangements, comprising either physical market or paper market (that is, shipping derivatives) investments, that is particular to the risk attitude of an individual decision maker.

Within this context, although the actual investment decisions taken will vary by both decision maker and over time, gaining information on the market dynamics and volatility correlations within a portfolio of assets or contracts remains the most appropriate starting point for approaching the decisionmaking process. Following the sharp drop in freight rates experienced across the whole shipping sector at the end of 2008, it is now even more so the case that any additional insight into the future direction of market volatility is of critical importance. To this end and using the Baltic Panamax route 2A and the Baltic Panamax route $3 \mathrm{~A}$ as sample markets, Yordan Leonov and Ventsislav Nikolov present an analysis of the fluctuations in freight rates on the two routes, which uses a hybrid model of wavelets and neural networks. The major advantage of this approach, suggest the authors, is that the wavelet multiscale decomposition of time series reveals volatility dynamics across different time frequencies that allow patterns in freight rates to be identified. By applying neural networks, these patterns can then be utilized for the purpose of predicting future freight rates.

The authors find that their model yields good approximations of predicted volatility in a series and provides a useful insight into volatility dynamics. They attribute the success of the proposed algorithm to the wavelet's ability to decompose the original series into a trend and local behaviour, which then serve as activation functions within a neural network learning algorithm. The authors conclude that multi-resolution wavelet analysis not only facilitates, but also motivates, the investigation of the relationship between volatilities at different scales, related to the rate of flow of information among players with different investment horizons. They go on to suggest that if the proposed algorithm were to be applied to the implied volatility of derivative contracts, then it could be used as a tool in spot price discovery.

There is certainly no doubt that liner shipping companies exert much greater control over the freight rates they charge than does a bulk sector that is exposed to the vagaries of demand and supply interacting in what is virtually a perfectly competitive free market. The major strategic concern of liner shipping companies does not lie, therefore, with the level of volatility in freight rates or with the associated need to forecast them therefore, but rather with the 
setting of prices across all time horizons that will facilitate the achievement of corporate objectives, probably the most generally applicable of which is profit maximization (or loss minimization). The objective of revenue (or yield) management is to maximize an organization's revenue with a view to maximizing profits (minimizing losses). This is achieved by guiding and supporting decisions related to the acceptance and pricing of bookings, as part of a general strategy of price discrimination through time.

Revenue management originated in the US airline industry, but did not really proliferate until the advent of the US Airline Deregulation Act of 1978 (Chiang et al, 2007). The gains from revenue management derived by the airline industry have been estimated as being in the order of between 2 per cent and 5 per cent (Belobaba and Wilson, 1997). It is now a practice that is widely employed in a number of industries, where the product offered conforms to certain fundamental and common characteristics as defined, for example, by Kasilingam (1996) and Hellermann (2006). Liner shipping provides a service that conforms to these required characteristics for the successful implementation of revenue management techniques. Indeed, as a consequence of the declining influence of the conference system within the sector, liner shipping would appear to be emerging as a particularly suitable arena for its implementation (Brooks and Button, 1994; Brooks, 2000).

In stark contrast to the airline industry, where revenue (yield) management is now extremely well established, the application of such techniques within the liner shipping industry remains very much in its infancy, with the main consideration in cargo booking strategy being the maximum utilization of ship capacity. This, of course, does not necessarily result in maximum revenue or profit. It is this conundrum that has prompted Sebastian Zurheide and Kathrin Fischer from the Institute for Operations Research and Information Systems at the Hamburg University of Technology to develop a slot allocation optimization model, which can be used to create booking limits for a liner shipping network where, in reality, transhipment between services is commonplace and demand may vary significantly over time. Their model explicitly accounts for different ship and booking cycles, a specific network structure and a variety of serviceoriented segments (including priority service for contract customers). Model outputs take the form of the booking limits that can be used to decide whether a booking should be accepted or rejected in favour of a possible later and potentially more beneficial booking.

The performance of the slot allocation model is evaluated on the basis of simulation results for a series of scenarios under different demand assumptions. Benchmarking against a booking system based on the 'first come, first served' principle, the results show that a strategy based on model outputs has a significant impact on the profit of a liner shipping company, with profits even

\footnotetext{
(C) 2012 Macmillan Publishers Ltd. 1479-2931 Maritime Economics \& Logistics Vol. 14, 3, 265-273 269
} 
doubling under certain scenarios. The authors suggest that this can be improved still further by developing the model to cater explicitly for additional factors such as customer value, cancellations and overbookings.

One of the most important costs incurred by shipping is that related to cargo handling in ports. In a contribution that narrowly missed out on the award of the MEL Prize for Best Paper, Beatriz Tovar and Alan Wall apply the theoretical work of Duncan (1990) to analyse how uncertainty in the demand for cargo handling affects the input choices and, therefore, the costs of production of port terminals. On the basis of panel data for three Spanish port terminals and incorporating demand uncertainty, the authors estimate a multiproduct cost system, comprising a cost function and a set of factor input demand equations. By benchmarking against a cost system that does not take demand uncertainty into account, their estimated cost function implies that: (i) sample companies contract a minimum number of payroll workers to deal with expected demand and then supplement this with non-payroll personnel on a flexible and ad hoc basis, once unexpected increases in demand materialize; (ii) supplementary inputs of land and non-port personnel are also required to cater for unexpected increases in demand and, as these factor inputs are quasifixed, this manifests itself as greater ex-ante renting of land or contracting of non-port personnel in advance of the realization of increased demand; and (iii) there are additional managerial and/or organizational costs associated with dealing with uncertain demand.

The estimation results also reveal that the lowest marginal costs relate to the handling of containers and that this falls significantly when demand uncertainty is accounted for. As might be expected, general cargo has the highest marginal costs. While accounting for demand uncertainty is found to have no significant influence over product-specific economies of scale, the results suggest that there are not only significant increases in economies of scale for the sample in aggregate, but also for each individual sample terminal. A further crucial result is that in each case, there are statistically significant increases in economies of scope when demand uncertainty is included. This implies the advantages of joint production, particularly the supplementary use of land and non-port workers as common inputs to provide a target service capacity.

Of vital importance to policymakers and regulators, estimates derived from a multi-product port terminal cost function yield information on: (i) company and/ or product marginal costs that are utilized in defining tariff caps; (ii) aggregate and product-specific economies of scale, which can aid in the development of an optimal tariff structure and policy decisions on intra-port competition and/or pricing regulation; and (iii) economies of scope, which can help in determining whether companies should be specialized or otherwise. The authors conclude, therefore, that the results of their analysis highlight the importance of correctly 
estimating port terminal cost functions on a company or product basis. Any failure to properly account for the influence that demand uncertainty exerts on costs may lead to biased estimates of these key measures and give rise to misleading policy recommendations in terms of pricing, optimal market structure and regulation.

The sort of port policy questions relating to competition and economies of scale which may be informed by the appropriate estimation of port cost functions are exactly those which are currently being faced in Hong Kong (Wang and Olivier, 2007; Sit, 2009; Ng, 2011). Since its reunification with Mainland China, Hong Kong's port has faced a number of challenges, not least the nature of its relationship with its competitors across the border in Shenzhen and Guangzhou and, partially as a consequence of this, shrinking demand for its services within its South China hinterland. Because of its special political and economic status under the concept of 'one country, two systems', Hong Kong has in the past remained largely independent from China's national and regional planning processes and has pursued policies which are founded on a principle of active non-interventionism that revolves around private-led initiatives. More recently, however, Hong Kong has been compelled to relent upon this approach and to attempt to gradually integrate itself into China's national and regional planning processes, particularly as they relate to the Pearl River Delta.

As a specific instance of this, under a new agreement signed with the Guangdong Provincial Government in 2010, the port of Hong Kong is now expected to play an integral part in a regional port cluster, with its activities complementing, rather than competing with, those of its competitor ports in the South China region. Exactly how this proposed regional port cluster should develop remains open to question, particularly in terms of the division of cargo flows between Hong Kong and the other major ports in South China. What is certain, however, is that the port of Hong Kong will be increasingly influenced by China's strategic planning at both national and regional levels and, of course, by its institutional framework and political system, thus significantly affecting the conventional understanding of port governance within the region.

Against this background, Kun Wang, Adolf Ng, Jasmine Siu Lee Lam and Xiaowen $\mathrm{Fu}$ develop a game theory model to investigate the factors and conditions affecting port governance in the region. On the basis of actual market data observed in 2010, their analytical model is calibrated to evaluate a possible alliance between Hong Kong and the ports of Shenzhen. The results of their analysis lead to a number of interesting conclusions. Most notably, that under certain conditions and in the absence of any regulatory barrier, ports in the South China cluster will be motivated to cooperate or form an alliance. The joint profit-maximizing behaviour of such an alliance would manifest itself as: (i) generally higher port prices; (ii) a consequentially lower aggregate throughput,

\footnotetext{
(C) 2012 Macmillan Publishers Ltd. 1479-2931 Maritime Economics \& Logistics Vol. 14, 3, 265-273 271
} 
the level of which depends on the degree of substitutability of services between ports in the cluster; and (c) the distribution of throughput across the cluster to minimize costs. If the anticipated or negotiated basis of this distribution of throughput is appropriately balanced such that all ports in the alliance have increased their profit levels, then alliance formation will be stimulated. Alternatively, if the negotiation of appropriate transfer payments is not precluded by regulation or for any other reason, then again the formation of an alliance will be attractive to all prospective members of the alliance. Where neither of these conditions is present, however, then there is little or no motivation for alliance formation.

We believe that the readership of this Special Issue of MEL will enjoy and benefit from our selection of the best papers presented at the IAME 2011 conference.

\section{References}

Belobaba, P.P. and Wilson, J.L. (1997) Impacts of yield management in competitive airline markets. Journal of Air Transport Management 3(1): 3-9.

Brooks, M.R. (2000) Sea Change in Liner Shipping. Oxford: Pergamon Press.

Brooks, M.R. and Button, K.J. (1994) Yield management: A phenomenon of the 1980s and 1990s? International Journal of Transport Economics 21(2): 177-196.

Brooks, M.R. and Trifts, V. (2008) Short sea shipping in North America: Understanding the requirements of Atlantic Canadian shippers. Maritime Policy and Management 35(2): 145-158.

Chen, S.M. (1996) Forecasting enrollments based on fuzzy time series. Fuzzy Sets and Systems 81(3): 311-319.

Chiang, W.C., Chen, J.C.H. and Xu, X. (2007) An overview of research on revenue management: Current issues and future research. International Journal of Revenue Management 1(1): 97-128.

Cullinane, K.P.B. (1995) A portfolio analysis of market investments in dry bulk shipping. Transportation Research B: Methodology 29B(3): 181-200.

Duncan, G.D. (1990) The effect of probabilistic demands on the structure of cost functions. Journal of Risk and Uncertainty 3(3): 211-220.

Hellermann, R. (2006) Capacity Options for Revenue Management. Berlin, Germany: Springer.

Kasilingam, R.G. (1996) Air cargo revenue management: Characteristics and complexities. European Journal of Operational Research 96(1): 36-44.

Markowitz, H.M. (1952) Portfolio selection. The Journal of Finance 7(1): 77-91.

Ng, A.K.Y. (2011) Container liner shipping, port development and competition. In: D.W. Song and P.M. Panayides (eds.) Maritime Logistics: Contemporary Issues. Bingley, UK: Emerald.

Puckett, S.M., Hensher, D.A., Brooks, M.R. and Trifts, V. (2011) Preferences for alternative short sea shipping opportunities: Valuation of travel time, reliability and frequency. Transportation Research E: Logistics and Transportation Review 47(2): 182-189.

Sit, V.F.S. (2009) Strategy for coordinated transport infrastructure development in the greater Pearl River Delta Region. Paper presented at the Seminar on Regional Planning in the Greater Pearl River Delta Region, Planning Department, Hong Kong SAR Government; 21 September.

Song, Q. and Chissom, B.S. (1993) Forecasting enrollments with fuzzy time series - Part I. Fuzzy Sets and Systems 54(1): 1-9.

272 (C) 2012 Macmillan Publishers Ltd. 1479-2931 Maritime Economics \& Logistics Vol. 14, 3, 265-273 
Song, Q. and Chissom, B.S. (1994) Forecasting enrollments with fuzzy time series - Part II. Fuzzy Sets and Systems 62(1): 1-8.

Wang, J.J. and Olivier, D. (2007) Hong Kong and Shenzhen: The nexus in South China. In: K.P.B. Cullinane and D.W. Song (eds.) Asian Container Ports: Development, Competition and Co-operation. New York: Palgrave Macmillan, pp. 198-212.

Zadeh, L.A. (1965) Fuzzy sets. Information and Control 8(3): 338-353.

Kevin Cullinane

Transport Research Institute, Edinburgh Napier University, Scotland

E-mail: k.cullinane@napier.ac.uk

Theo Notteboom

Institute of Transport and Maritime Management Antwerp (ITMMA),

University of Antwerp, Belgium

E-mail: theo.notteboom@ua.ac.be

Ricardo Sanchez

Infrastructure Services Unit, Natural Resources and Infrastructure Division,

UNECLAC, Chile

E-mail: ricardo.sanchez@cepal.org

Gordon Wilmsmeier

Infrastructure Services Unit, Natural Resources and Infrastructure Division,

UNECLAC, Chile

E-mail: Gordon.Wilmsmeier@cepal.org

(C) 2012 Macmillan Publishers Ltd. 1479-2931 Maritime Economics \& Logistics Vol. 14, 3, 265-273 273 